\title{
Thermal-Shock Resistance and Fracture-Strength Behavior of Two Tool Carbides
}

\author{
Y. W. MAI* \\ Department of Mechanical Engineering, University of Michigan, Ann Arbor, Michigan 48104
}

\begin{abstract}
The thermal-stress resistance and fracture-strength behavior of TiC and WC after severe thermal shocking were investigated. The damage-resistance parameter, $\left(K_{\mathrm{Ic}} / \sigma_{f}\right)^{2}$, for both carbides was determined over a wide range of loading rates and temperatures. The fracture-strength behavior of these two carbides in the quenching temperature range of $25^{\circ}$ to $800^{\circ} \mathrm{C}$ follows Hasselman's model for an instantaneous strength loss at a critical quenching temperature. When WC was shocked at temperatures $>800^{\circ} \mathrm{C}$, it exhibited higher retained strengths because of its higher $\left(K_{\mathrm{I} c} / \sigma_{f}\right)^{2}$ values at these temperatures. The effects of specimen size and repeated thermal shocks on retained strength and critical quenching temperature for these carbides were also investigated.
\end{abstract}

\section{Introduction}

A LTHOUGH thermal-shock-induced fracture in carbide tools during cutting operations is not uncommon, it has received relatively little attention. Mai and Atkins ${ }^{1}$ have successfully applied Hasselman' $\mathrm{s}^{2}$ unified theory of thermal-shock failure to examine the retained-strength $\left(\sigma_{a}\right)$ behavior of some tool carbides after they have been shocked through their respective critical quenching temperatures $\left(T_{c}\right)$. The $\sigma_{a}$ was low because the preexisting small internal flaws in the carbides grew during the critical shock. Mai and Atkins ${ }^{1}$ suggested that carbide tools could be compared according to both their resistance to crack initiation and their resistance to crack propagation (i.e. extent of damage). For crack initiation caused by thermal shock, the appropriate parameter is $k \sigma_{f} / E \alpha$, where $k$ is thermal conductivity, $\sigma_{f}$ tensile fracture strength, $E$ Young's modulus, and $\alpha$ the coefficient of linear expansion of the ceramic under consideration. The larger the value for $k \sigma_{f} / E \alpha$ the lesser the chance that flaws will be initiated. Damage resistance or extent of crack propagation by thermal shock is best characterized by the magnitude of $\left(K_{\mathrm{I}} / \sigma_{f}\right)^{2}$, where $K_{\mathrm{I} c}$ is fracture toughness. Ceramics can also be ranked by a more traditional method in which small specimens are successively subjected to thermal cycles with increasing shock severity. The number of cycles required to cause the appearance of surface cracks and final fracture, respectively, are recorded and the results are used to rate the ceramics.

The present paper reports the results of an experimental investigation on the thermal-shock resistance and fracture-strength behavior of two cemented carbides (a tungsten carbide and a titanium carbide). Both $\left(K_{\mathrm{I}} / \sigma_{f}\right)^{2}$ and the retained strengths for these carbides are determined as a function of temperature $\left(25^{\circ}\right.$ to $\left.1000^{\circ} \mathrm{C}\right)$, and possible influences of loading rates and the effects of different surface finishes are investigated.

\section{Experimental Procedure}

\section{(1) Preparation of Materials}

The WC ${ }^{\ddagger}$ was blended with $8.5 \%$ cobalt and has the composition $\mathrm{WC} / \mathrm{TiC} / \mathrm{TaC} / \mathrm{Co}$ in the ratio (in $\mathrm{wt} \%$ ) of $72: 8: 11.5: 8.5$. The $\mathrm{TiC}^{\S}$

\footnotetext{
Received September 26, 1975; revised copy received July 17, 1976.

Supported by General Motors Corporation.

* Now with the Department of Mechanical Engineering, Imperial College of Science and Technology, Exhibition Road, London SW7 2BX, England.

$f\left(K_{\mathrm{Ic}} / \sigma_{f}\right)^{2}$ in fracture mechanics describes the size of the plastic zone at the crack tip (Ref. 3). Recent research also shows that this quantity characterizes the transition of quasi-static cracking to generalized yielding (Ref, 4) and that it can rank the machinability of materials (Ref. 5).

†Carboloy 370, General Electric Co., Detroit, Mich.

§Titan 80, Adamas Co., Livonia, Mich.
}

Table I. Mechanical and Physical Properties of Carbides

\begin{tabular}{lcc}
\hline Property & TiC & WC \\
\hline$k(\mathrm{cal} / \mathrm{s} \mathrm{C} \mathrm{cm})$ & 0.04 & 0.11 \\
$\sigma_{f}\left(\mathrm{MN} / \mathrm{m}^{2}\right)$ & 500 & 1680 \\
$E\left(\mathrm{GN} / \mathrm{m}^{2}\right)$ & 446 & 560 \\
$\nu^{*}$ & 0.20 & 0.23 \\
$\alpha^{\dagger}\left({ }^{\circ} \mathrm{C}^{-1}\right)$ & $2.40 \times 10^{-6}$ & $5.70 \times 10^{-6}$ \\
$\beta^{*}$ & 8.10 & 2.96 \\
\hline
\end{tabular}

*Poisson's ratio; tcoefficient of linear expansion; $¥$ Biot's modulus.

was blended with Ni and Mo alloys. Table I compares some of their physical and mechanical properties. Both $\mathrm{WC}$ and $\mathrm{TiC}$ were prepared with two surface conditions, one the as-sintered condition and the other diamond-ground to $\approx 0.25$ to $0.50 \mu \mathrm{m}$ rms which approximates the surface finish of the actual tool inserts.

\section{(2) Measurement of Temperature-Dependent and Retained Strength}

Three-point bend specimens with the grinding direction parallel to the longitudinal axis were prepared by the manufacturers. The specimen edges were slightly rounded to eliminate chipping along these edges during the tests. Strength was determined between $25^{\circ}$ and $800^{\circ} \mathrm{C}$ in air at a loading rate of $83.3 \mu \mathrm{m} / \mathrm{s}$. The after-shock room-temperature retained strengths $\left(\sigma_{a}\right)$ were determined by quenching from $200^{\circ}$ to $1000^{\circ} \mathrm{C}$; specimens were equilibrated in an electric furnace to the required temperature and quenched in a water bath at $\approx 20^{\circ} \mathrm{C}$. The time required to transfer specimens to the quenching medium was $\approx 1 \mathrm{~s}$.

\section{(3) Determination of Fracture Toughness}

Fracture toughness values for both $\mathrm{WC}$ and $\mathrm{TiC}$ were determined using bend specimens containing semielliptical surface precracks, which were introduced in the test pieces by surface indentation using a Vickers hardness tester with a 40-kg applied load and a Knoop diamond indenter. This procedure gave very consistent precracks $\approx 0.70$ to $0.80 \mathrm{~mm}$ long $(2 a)$ and $\approx 0.30 \mathrm{~mm}$ deep $(b)$, which could be determined from the fracture surfaces (see Fig. 1). Success with this method of precracking cemented tungsten carbides has been reported previously by Kenny ${ }^{6}$ and Ingelstrom and Nordberg. ${ }^{7}$ The fracture toughness $\left(K_{\mathrm{I}}\right)$ under 3-point bend cracking may be determined by ${ }^{7}$ :

$$
\begin{aligned}
& K_{\mathrm{Ic}}=3 / 2 \frac{X L b^{1 / 2}}{B W^{2}}\left[1.96-2.75\left(\frac{b}{W}\right)+13.66\left(\frac{b}{W}\right)^{2}\right. \\
& \left.-23.98\left(\frac{b}{W}\right)^{3}+25.22\left(\frac{b}{W}\right)^{4}\right] \Phi^{-1}
\end{aligned}
$$

when $\Phi$, the elliptical integral, is given by

$$
\Phi=\int_{0}^{\pi / 2}\left(1-\frac{a^{2}-b^{2}}{a^{2}} \sin ^{2} \theta\right)^{1 / 2} d \theta
$$

In Eq. (1), $X$ is the fracture load, $L$ the length of span, $B$ and $W$ specimen thickness and depth, and $b$ and $a$ are the semiminor and semimajor axes of the surface precrack.

Where possible, $K_{\text {Ic }}$ was also estimated by investigating the fracture surfaces of those bend specimens that were used for measuring $\sigma_{a}$ (Section II(2)) and establishing the flaw size from which the final break occurred. The $\mathrm{K}_{\mathrm{I} c}$ results for both $\mathrm{TiC}$ and WC 


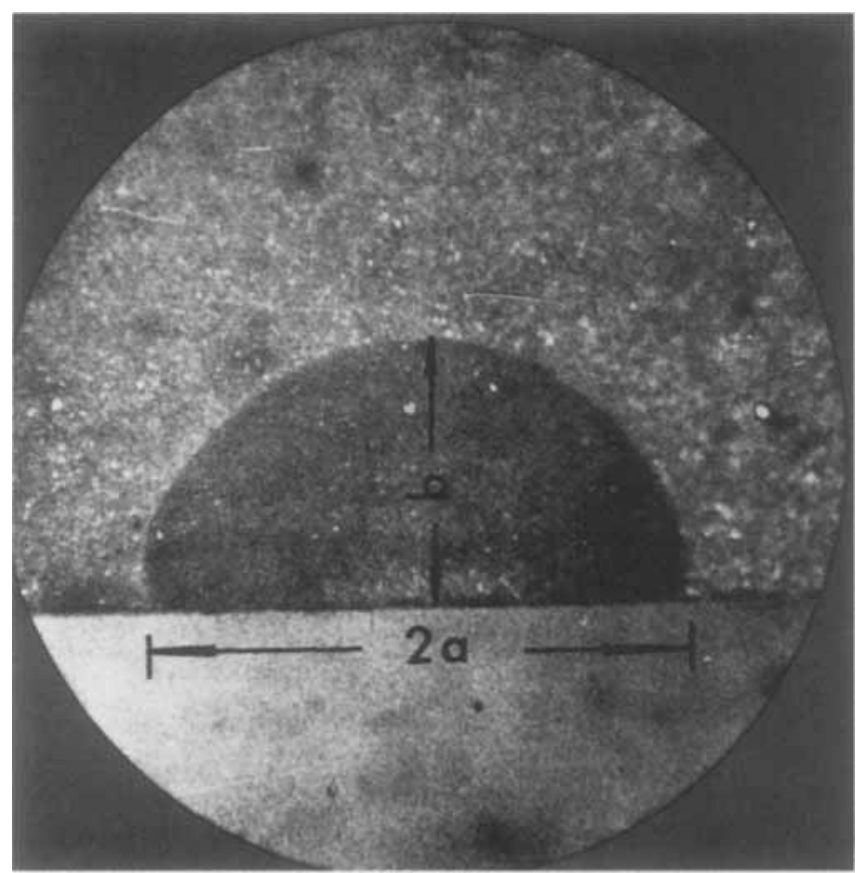

Fig. 1. A typical semielliptical surface crack introduced by the indentation technique. $(\mathrm{TiC}, \times 80)$.

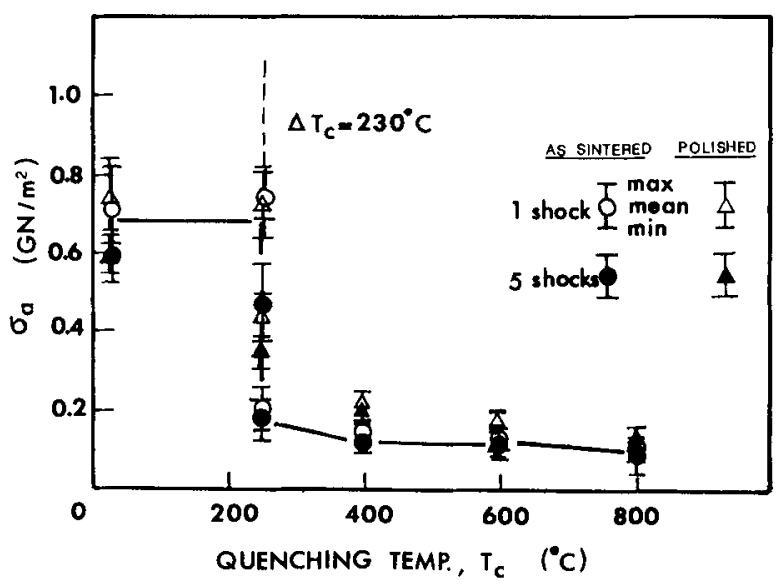

Fig. 2. Strength variation of $\mathrm{TiC}$ with quenching temperature.

were also obtained as a function of temperature and crosshead rate $(0.05$ to $25 \mathrm{~cm} / \mathrm{min})$.

\section{Results and Discussion}

(1) Effect of Thermal Shock, Temperature, and Loading Rate on Bend Strength

Figures 2 and 3 show the retained room-temperature strength $\left(\sigma_{a}\right)$ plotted vs the shocking temperature interval for TiC and WC in both the as-sintered and polished surface conditions. The TiC obviously follows the Hasselman ${ }^{2}$ model, which shows a distinct discontinuity with considerable strength loss at a critical quenching temperature $\left(T_{c}\right)$. As shown by Manson, ${ }^{8}$ this $T_{c}$ may be obtained by equating the maximum surface stress during thermal shock to the strength of the carbide in the shock environment. Thus, we obtain ${ }^{9}$

$$
\Delta T_{e}=\left(T_{c}-T_{w}\right) \simeq \frac{\sigma_{f}(1-\nu)}{3 E \alpha \psi}
$$

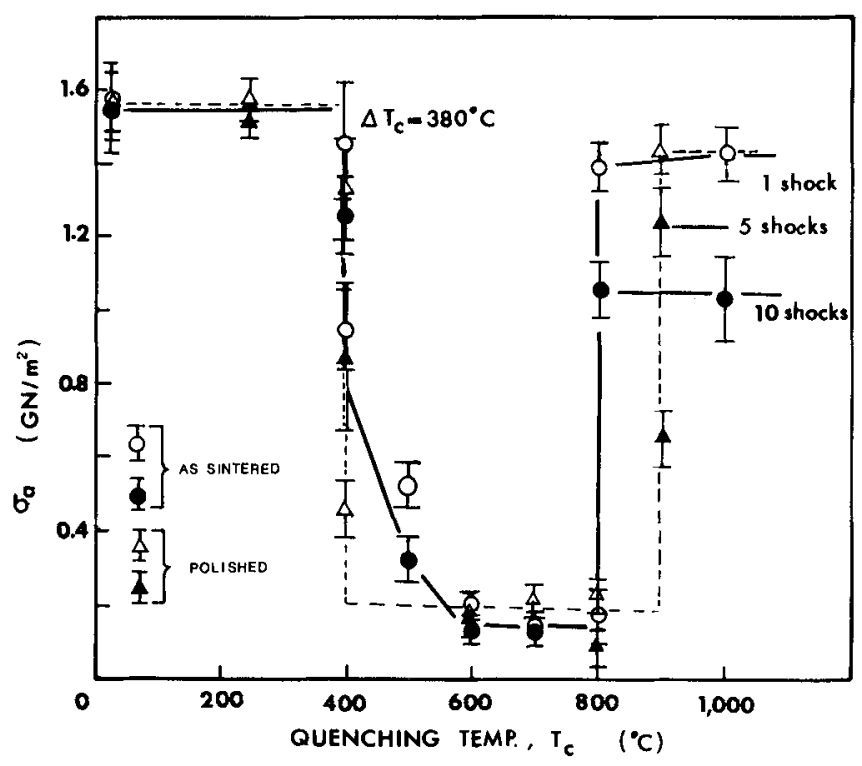

Fig. 3. Strength variation of WC with quenching temperature.

and

$$
\psi^{-1}=1.50+\frac{3.25}{\beta}-0.5 \exp -\frac{16}{\beta}
$$

where $\nu$ is Poisson's ratio, $\alpha$ is the coefficient of linear expansion, $T_{w}$ is the temperature of the water bath, $\beta$ is the Biot modulus $(=d h / k) ; d$ is half the thickness of the test piece, $h$ the heat-transfer coefficient, and $k$ thermal conductivity. Although $h$ may be dependent on the quenching temperature difference $(\Delta T)$, values of 1 to 2 cgs units are not unreasonable. 9 ** Thus, when the values for $\sigma_{f}, E, \alpha$, and $\nu$ as given in Table I are substituted into Eq. ( $3 a$ ), $\Delta T_{c}$ for $\mathrm{TiC}$ is $\approx 250^{\circ} \mathrm{C}$ when $h=1 \mathrm{cgs}$ unit and $208^{\circ} \mathrm{C}$ when $h=2$ cgs units. These values agree well with the experimental result $\left(230^{\circ} \mathrm{C}\right)$ shown in Fig. 2.

The $\sigma_{a}$ for WC below a quenching temperature of $800^{\circ} \mathrm{C}$ can also be described by Hasselman's model. From Fig. 3, the discontinuity in the plot of the retained strength vs shocking temperature occurred at $\approx 400^{\circ} \mathrm{C}$. This result compares fairly well with the theoretical calculations which give $\Delta T_{c}=375^{\circ} \mathrm{C}$ for $h=1 \mathrm{cgs}$ and $310^{\circ} \mathrm{C}$ for $h=2 \mathrm{cgs}$.

It should also be noted that, for both $\mathrm{WC}$ and $\mathrm{TiC}, T_{c}$ does not appear to depend on the surface-finish condition (see Figs. 2 and 3), thus indicating that the original internal flaw sizes are the same. This similarity in flaw sizes is also supported by the fact that the unquenched strengths of both carbides, as shown in Figs. 2 and 3, are similar for the two surface finishes.

Experiments have shown that loading rates within the range 8.33 $\times 10^{-6}$ to $2.5 \mathrm{~m} / \mathrm{s}$ have negligible effects on $\sigma_{f}$ for both the assintered and polished WC and TiC. Three-point unshocked bend strengths ${ }^{\dagger}$ of $\mathrm{TiC}$ and WC (for specimens 6.5 by 5.6 by $38 \mathrm{~mm}$ ) in the range $25^{\circ} \mathrm{C}(R T)$ to $800^{\circ} \mathrm{C}$ in both the as-sintered and polished condition remained constant to $\approx 600^{\circ} \mathrm{C}$. The strength of $\mathrm{TiC}$ was 480 to $500 \mathrm{MN} / \mathrm{m}^{2}$, independent of surface finish, whereas the strength of $W C$ was $\approx 1.5$ and $\approx 1.7 \mathrm{GN} / \mathrm{m}^{2}$ in the as-sintered and polished conditions, respectively. At $800^{\circ} \mathrm{C}$, both carbides display some strength loss as a result of subcritical crack growth caused by plastic deformation within the metal phase; nonlinearities were observed in the load/time traces before final fracture.

*It has been suggested (Ref. 10) that, for a water quench, $h \simeq 0.1 \mathrm{cgs}$ unit. However, for this value of $h$, the critical quenching temperature differences for TiC and WC are $600^{\circ}$ and $1700^{\circ} \mathrm{C}$, respectively. Since these results are far greater than those observed experimentally, $h \simeq 1$ to 2 cgs units (as suggested in Ref. 9) was chosen in the present $\Delta T_{c}$ calculations.

†Note that in smaller specimens ( 5 by 2.8 by $30 \mathrm{~mm}$ for WC and 2.5 by 2.5 by $25 \mathrm{~mm}$ for $\mathrm{TiC}$ ) the unshocked bend strengths are $25 \%$ and $100 \%$ stronger for $\mathrm{WC}$ and $\mathrm{TiC}$, respectively. 
As shown in Figs. 2 and 3, $\sigma_{a}$ for $\mathrm{WC}$ and $\mathrm{TiC}$ is independent of the number of repeated shocks for $25^{\circ} \mathrm{C}<T<800^{\circ} \mathrm{C}$. However, at $\approx 800^{\circ} \mathrm{C}$, thermal fatigue effects caused by repeated shocks were observed in WC since internal flaws grew during each shock. The retained strength must, therefore, decrease with the number of repeated shocks, as shown in Fig. 3.

\section{(2) Fracture Toughness Results}

As pointed out by Ingelstrom and Nordberg, ${ }^{7}$ valid $K_{\mathrm{I} c}$ results can be obtained for the two carbides only when the residual stresses around the indentation precrack are relieved. Thus, the specimens were annealed at $800^{\circ} \mathrm{C}$ for $30 \mathrm{~min}$ and fractured in 3-point bending in the range $25^{\circ}$ to $1000^{\circ} \mathrm{C}$. Values for $K_{\mathrm{I} c}$ thus obtained for WC and $\mathrm{TiC}$ (both surface finishes) were $\approx 13 \mathrm{MN} / \mathrm{m}^{3 / 2}$ and $7.5 \mathrm{MN} /$ $\mathrm{m}^{3 / 2}$, respectively, and remained relatively constant throughout the range $25^{\circ}$ to $800^{\circ} \mathrm{C}$. Much higher $K_{\text {Ic }}$ values were measured for both carbides above $800^{\circ} \mathrm{C}$, e.g. at $1000^{\circ} \mathrm{C}, K_{\mathrm{Ic}}$ was 10 and 15 $\mathrm{MN} / \mathrm{m}^{3 / 2}$ for TiC and WC, respectively. It seems that such increases in $K_{\mathrm{Ic}}$ are caused either by crack-tip blunting resulting from plastic deformation in the metal binders or by multiple cracking caused by separation of grain boundaries.

Useful estimates of $K_{\mathrm{I} e}$ were also obtained from the $\sigma_{a}$ experiments for the thermally shocked carbide specimens. When the final crack size $\left(r_{f}\right)$ and geometry (i.e. part-through or through crack) from the fracture surfaces of the shocked specimens were noted and the corresponding $\sigma_{a}$ in 3-point bending was used, $K_{\mathrm{Ic}}$ was obtained by plotting $\sigma_{a} Y$ vs $\left(\sqrt{r_{f}}\right)^{-1}$. Note that $Y$ is a correction factor for the particular crack geometry of the after-shock test sample and may be found from the work of Brown and Srawley. ${ }^{11}$ For instance, Fig. $4(A)$ shows such a plot for the as-sintered WC; the slope of this line gives a toughness value of $\approx 13.33 \mathrm{MN} / \mathrm{m}^{3 / 2}$. Figure $4(B)$ shows 2 typical fracture surfaces from which $r_{f}$ can be measured. Similarly, the $K_{\mathrm{Ic}}$ value for TiC deduced from $\sigma_{a}$ experiments is $\approx 7.2 \mathrm{MN} / \mathrm{m}^{3 / 2}$. These $K_{\text {Ic }}$ results agree very well with those obtained previously from specimens free of residual stress effects. The $K_{\mathrm{I} c}$ values for both the as-sintered and polished $\mathrm{TiC}$ and $\mathrm{WC}$ were not affected by the loading rates used in the testing machine.*

(3) Relation Between Strength Loss and $\left(K_{\mathrm{Ic}} / \sigma_{f}\right)^{2}$ Parameter

According to the analysis of Hasselman, ${ }^{2}$ the fractional $\sigma_{a}$ of a rectangular beam subjected to critical thermal shock is approximated by ${ }^{12}$

$$
\frac{\sigma_{a}}{\sigma_{f}}=\left[0.32 \pi\left(1-\nu^{2}\right) \frac{N}{V}\right]^{1 / 4}\left(\frac{K_{\mathrm{I} c}}{\sigma_{f}}\right)^{3 / 2}
$$

where $N / V$ is the number of cracks per unit volume of the stressed specimen. Since $N / V$ is difficult to measure, an approximate relation in which $N / V \simeq N_{s}^{3 / 2}$ is used, where $N_{s}$ is the area density of cracks measurable from the shocked samples. This approach was used to measure $N_{s}$ for $\mathrm{TiC}$ and $\mathrm{WC}$ at their respective $T_{c}$; the resultant values were converted to $N / V$, which was $7.6 \times 10^{7}$ cracks/ $\mathrm{m}^{3}$ and $1.5 \times 10^{8} \mathrm{cracks} / \mathrm{m}^{3}$, respectively. Hence, in conjunction with appropriate $\left(K_{\mathrm{Ic}} / \sigma_{f}\right)^{2}$ values at their corresponding $\Delta T_{c}$ from Table II, $\sigma_{a} / \sigma_{f}$ for $\mathrm{TiC}$ and $\mathrm{WC}$ is 0.23 and 0.12 , respectively. These results should be compared with the observed values of 0.20 to 0.25 for $\mathrm{TiC}$ and 0.08 to 0.16 for WC.

The considerable strength regained by thermally shocked WC samples above $800^{\circ} \mathrm{C}$ was suggested previously to be a result of the oxidation effect. ${ }^{1}$ However, it is now believed that since, as shown in Table II, the $\left(K_{\mathrm{Ic}} / \sigma_{f}\right)^{2}$ values above $800^{\circ} \mathrm{C}$ are much greater than the corresponding value at room temperature, the cracks propagated after shocking at these high temperatures must be much smaller than those shocked through lower temperatures (where the $\left(K_{\mathrm{Ic}} /\right.$ $\left.\sigma_{f}\right)^{2}$ values are lower). Consequently, these shocked specimens display higher $\sigma_{a}$, as shown in Fig. 3.

(4) Effects of Size on $\sigma_{a}$ and $\Delta T_{c}$

Three major effects are associated with the size of the ceramic specimens: (1) Smaller specimens give higher $\sigma_{f}$ values, presumably a result of a statistical distribution of flaws (Weibull' ${ }^{13}$

*Instron Corp., Canton, Mass.
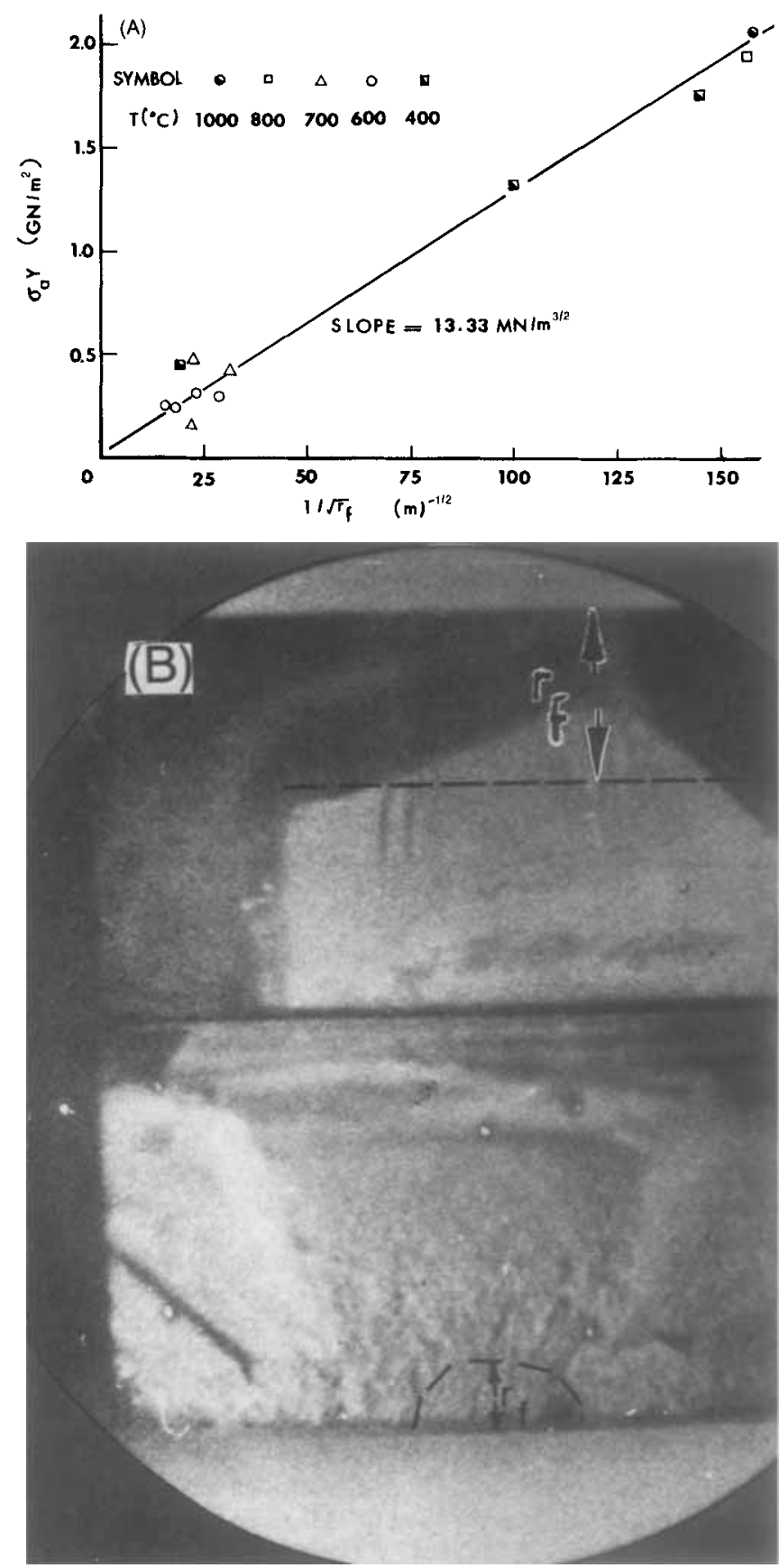

Fig. 4. (A) "Corrected" stress $\sigma_{a} Y$ plotted vs $1 / \sqrt{r_{f}}$ for assintered WC. (B) Typical fracture surfaces with thermalshock-induced cracks.

Table II. Variation of $\left(K_{\mathrm{Ic}} / \sigma_{f}\right)^{2}$ with Temperature

\begin{tabular}{lcccc}
\hline & \multicolumn{4}{c}{ Temperature $\left({ }^{\circ} \mathrm{C}\right)$} \\
\cline { 3 - 5 } \multicolumn{1}{c}{ Material } & $25-400$ & 600 & 800 & 1000 \\
\hline WC & \multicolumn{4}{c}{$\left(K_{\mathrm{Ic}} / \sigma_{f}\right)^{2}(\mu \mathrm{m})$} \\
$\quad$ Polished & 52.0 & 53.0 & 55.0 & 110 \\
$\quad$ As-sintered & 59.5 & 60.2 & 69.6 & 117 \\
TiC & & & & \\
$\quad$ Polished & 136 & 136 & 250 & 870 \\
$\quad$ As-sintered & 136 & 136 & 250 & 692 \\
\hline
\end{tabular}

weakest-link theory). (2) When quenching conditions are equal, smaller specimens - because of their smaller Biot modulus $(\beta)-$ will yield larger $\Delta T_{c}$ values. Table III shows such results on $\Delta T_{c}$ 
Table III. Size Effects on Experimentally Observed Values for $\Delta T_{c}$ and $\sigma_{a}$ for Titanium and Tungsten Carbides

\begin{tabular}{ccccc} 
& & \multicolumn{3}{c}{ Specimen size* } \\
\cline { 3 - 5 } Material & Quantity & A & B & \multicolumn{1}{c}{$\mathrm{C}$} \\
\hline WC & $\Delta T_{c}\left({ }^{\circ} \mathrm{C}\right)$ & $\dagger$ & 550 & 380 \\
& $\sigma_{a}\left(\mathrm{MN} / \mathrm{m}^{2}\right)$ & $\dagger$ & 500 & $120-260$ \\
TiC & $\Delta T_{c}\left({ }^{\circ} \mathrm{C}\right)$ & 400 & 450 & 230 \\
& $\sigma_{a}\left(\mathrm{MN} / \mathrm{m}^{2}\right)$ & 150 & 120 & $120-200$ \\
\hline
\end{tabular}

${ }^{*} \mathrm{~A}=2.5$ by 2.5 by $25 \mathrm{~mm} ; \mathrm{B}=5$ by 2.8 by $30 \mathrm{~mm} ; \mathrm{C}=6.5$ by 5.6 by $38 \mathrm{~mm}$. †"Continuous" strength behavior, no instantaneous drop observed.

for TiC and WC for 3 test piece sizes. (3) Because $N / V$ increases with decreasing specimen size, $\sigma_{a}$ may also increase, as shown by the $\sigma_{a}$ results in Table III. As a result, it is also plausible that the $\sigma_{a}$ behavior can change qualitatively from catastrophic to gradual. For example, the "continuous" fracture mode observed in much smaller WC specimens* (size A in Table III) after thermal shock ${ }^{3}$ has changed to a "discontinuous" behavior in sufficiently large specimens.

\section{(5) Comparisons of Thermal Stress Resistance}

The thermal-shock stress resistance of these two carbides may be compared using one of several methods: (1) traditional evaluation of thermal-shock stress resistance, (2) determination of $T_{c}$ at which thermal cracks initiate, and (3) evaluation of the percentage of strength retained after shocking through $\Delta T_{c}$. The first method has been described in detail in Ref. 1. Results for TiC and WC are given in Table IV. Apparently, these results can be correlated with the parameters $k \sigma_{f} / E \alpha$ and $\left(K_{\mathrm{I} c} / \sigma_{f}\right)^{2}$ for crack initiation and crack propagation, respectively. Based on crack initiation, WC is better because of its higher $k \sigma_{f} / E \alpha$ value, but based on final fracture, $\mathrm{TiC}$ is superior because of its higher $\left(K_{\mathrm{Ic}} / \sigma_{f}\right)^{2}$ value. With method (2), where resistance to crack initiation is compared, the experimental results (see Figs. 2 and 3) show that $\mathrm{WC}$ is preferable to TiC because of its higher $T_{c}$ values (i.e. $T_{c} \simeq 400^{\circ} \mathrm{C}$ as opposed to $T_{c} \simeq 250^{\circ} \mathrm{C}$ in $\mathrm{TiC}$ ). This result is not unexpected since WC has much greater $\sigma_{f} / E$ and $k$ values. However, when method (3) is used as a criterion for comparison, $\mathrm{TiC}$ is preferable to $\mathrm{WC}$ for the quenching temperature range of $400^{\circ}$ to $800^{\circ} \mathrm{C}$. (See results in Figs. 2 and 3.) The two surface finishes do not appear to affect the thermal stress resistance for both $\mathrm{TiC}$ and $\mathrm{WC}$ in the present considerations.

\section{Conclusions}

The $\left(K_{\mathrm{Ic}} / \sigma_{f}\right)^{2}$ parameter for both titanium and tungsten carbides has been determined and found to be independent of both loading rate $\left(8.33 \times 10^{-6}\right.$ to $\left.2.5 \mathrm{~m} / \mathrm{s}\right)$ and temperature $\left(<800^{\circ} \mathrm{C}\right)$. The fracture-strength behavior of both carbides in the thermal-shock range of $25^{\circ}$ to $800^{\circ} \mathrm{C}$ may be explained in terms of Hasselman's model. Instantaneous strength loss at $T_{c}$ calculated using $\left(K_{\mathrm{I} c} / \sigma_{f}\right)^{2}$ values at $T_{c}$ agree reasonably well with experimental results.

\footnotetext{
*This continuous fracture strength behavior in WC after thermal shocking is shown in Fig. 1 of Ref. 3.
}

Table IV. Evaluation of Thermal-Shock Resistance for WC and TiC

\begin{tabular}{|c|c|c|c|c|c|c|c|c|c|}
\hline \multirow[b]{2}{*}{ Material } & \multicolumn{7}{|c|}{$\begin{array}{l}\text { Thermal cycles (to temp. }\left({ }^{\circ} \mathrm{C}\right) \text { specified) } \\
\text { completed before failure }\end{array}$} & \multicolumn{2}{|c|}{$\begin{array}{c}\text { Thermal-shock } \\
\text { parameters }\end{array}$} \\
\hline & 260 & 300 & 400 & 600 & 800 & 1000 & $N_{f}$ & $\begin{array}{c}k \sigma_{f} / E \alpha \\
\left(\mathrm{cal} / \mathrm{cm}^{-1} \mathrm{~s}^{-1}\right)\end{array}$ & $\begin{array}{c}\left(K_{\mathrm{I} c} / \sigma_{f}\right)^{2} \\
(\mu \mathrm{m})\end{array}$ \\
\hline $\mathrm{TiC}$ & 10 & 10 & $10(5$ & 110 & 10 & 4 & 54 & 20.6 & 136 \\
\hline WC & 10 & 10 & 10 & $10(1)$ & 10 & & 50 & 54.7 & 52 \\
\hline
\end{tabular}

*Parentheses indicate cycles required for initiation of surface cracks. The specimens were 6.5 by 5.6 by $38 \mathrm{~mm}$.

The considerable strength regained by WC samples shocked through temperatures above $800^{\circ} \mathrm{C}$ is attributed to its much higher $\left(K_{\mathrm{Ic}} / \sigma_{f}\right)^{2}$ values resulting from plastic deformation in the metal phase at these temperatures. The effects of specimen size and repeated shocks on $\Delta T_{c}$ and $\sigma_{a}$ of the thermally shocked carbides have also been investigated.

Although, in the evaluation of the overall performance of ceramic and carbide cutting tools, resistance to thermal-shock fracture is only one of many pertinent considerations, it represents a very practical aspect in design and material selection if tool failure is to be minimized. The present work provides some useful information and procedures which may be adopted to investigate thermal shock behavior of other ceramic and carbide cutting tools, e.g. see Ref. 14.

Acknowledgments: The writer thanks Jamie Hsu of the General Motors Technical Center and A. G. Atkins of Delta Materials Research Limited for many helpful discussions. Some of the carbide specimens were specially prepared by the manufacturers concerned and the present results are, therefore, not necessarily typical of commercial products.

\section{References}

${ }^{1}$ Y. W. Mai and A. G. Atkins, "Fracture Toughness and Thermal Shock of Tool and Turbine Ceramics," J. Mater. Sci., 10 [11] 1904-19 (1975).

${ }^{2}$ D. P. H. Hasselman, "Unified Theory of Thermal Shock Fracture Initiation and Crack Propagation in Brittle Ceramics,"J. Am. Ceram. Soc., 52[11] 600-604 (1969).

${ }^{3} \mathrm{G}$. R. Irwin; pp. IV-63-IV-78 in Mechanical and Metallurgical Behavior of Sheet Materials. Syracuse University Press, 1960

${ }^{4}$ C. Gumey, Y. W. Mai, and R. C. Owen, " Quasi-Static Cracking of Materials with High Fracture Toughness and Low Yield Stress," Proc. R. Soc. London, Ser. A, 340 [1621] 213-31 (1974).

5 A. G. Atkins, "Fracture Toughness and Cutting," Int. J. Prod. Res., 12 [2] 263-74 (1974).

'P. Kenny, "Applícation of Fracture Mechanics to Cemented Tungsten Carbides," Powder Metall., 14 [27] 22-38 (1971).

${ }^{7} \mathbf{N}$. Ingelstrom and $\mathbf{H}$. Nordberg, "Fracture Toughness of Cemented Tungsten Carbides,"Eng. Fract. Mech., 6 [3] 597-607 (1974).

8 S. S. Manson, "Behavior of Materials Under Conditions of Thermal Stress," Natl. Advis. Comm. Aeronaut., Tech. Note 2933, July, 1953.

"R. W. Davidge and G. Tappin, "Thermal Shock and Fracture in Ceramics," Trans. Br. Ceram. Soc., 66 [8] 405-22 (1967).

${ }^{10}$ D. P. H. Hasselman, R. Badaliance, K. R. McKinney, and C. H. Kim, "Failure Prediction of the Thermal Fatigue Resistance of a Glass," I. Mater. Sci., 11 [3] 458-64 (1976)

${ }_{11}$ W. F. Brown and J. E. Srawley, "Plane Strain Crack Toughness Testing of High-Strength Metallic Materials," Am. Soc. Test. Mater., Spec. Tech. Publ., No. 410,$1967 ; 129 \mathrm{pp}$.

${ }_{12}$ Y. W. Mai and A. G. Atkins, "Fracture Strength Behavior of Tool Carbides Subjected to Severe Thermal Shock," Am. Ceram. Soc. Bull., 54 [6] 593 (1975).

${ }_{13} \mathrm{~W}$. Weibull, "Statistical Theory of Strength of Materials," Ingenioersvetenskapsakad., Handl., 1939, No. $151 ; 45$ pp.

${ }^{14}$ Y. W. Mai, "Thermal Stress Resistance and Fracture Toughness of Two Tool Ceramics," J. Mater. Sci., 11 [8] 1430-38 (1976). 